\title{
Process optimization in the development of porang glucomannan (Amorphophallus mulleri $B$.) incorporated into the restructured rice using a pasta extruder: physicochemical properties, cooking characteristics, and an estimated glycemic index
}

\author{
Domas Galih PATRIA ${ }^{1}$, Aji SUTRISNO², Sukamto SUKAMTO³ Jenshinn LIN ${ }^{4 *}$ (])
}

\begin{abstract}
This study aims to find out the optimum treatment of the feed moisture in porang glucomannan (PGM), and $\mathrm{Ca}(\mathrm{OH})_{2}$ in the production of the restructured rice using a pasta extruder. Feed moisture (35-45\%), PGM (3-7\%), and $\mathrm{Ca}(\mathrm{OH})_{2}(0.04-0.10 \%)$ were the independent variables, while the water absorption index (WAI), the water soluble index (WSI), whiteness, and hardness were responses using a response surface methodology (RSM). Data were analyzed for the chemical components, the 3D surface, the microstructure, the cooking characteristics, and the estimated glycemic index (eGI). The results reported that the WAI and WSI ranged from 2.904 to $3.99 \mathrm{~g} / \mathrm{g}$ and 2.018 to $3.302 \%$, respectively, whereas whiteness and hardness ranged from 72.83 to 85.02 and 4.921 to $7.537 \mathrm{kgf}$. The chemical components, the cooking characteristics, and the eGI of the optimum restructured rice PGM reported a significant difference when they were compared to milled rice. The result of the 3D surface of the optimum restructured rice with PGM is similar to milled rice which is seen to be like a convex shape.
\end{abstract}

Keywords: calcium hydroxide; glycemic index; pasta extruder; porang glucomannan; restructured rice; 3D surface.

Practical Application: Restructured rice can be a part of human consumption to lower obesity and diabetes case in the world.

\section{Introduction}

Rice (Oryza sativa L.) is one of the most commonly produced and consumed grains in the world, characterized as the main food source for more than half the world's population (Amin et al., 2017). Rice is the prime food for about 3.5 billion people worldwide, especially Asians who consume more than $90 \%$ of the total rice produced globally as it is staple food (Mohanty, 2013). People living a sedentary lifestyle and overeating foods, especially rice, are likely to invite health complications like type II diabetes and obesity (Kumar et al., 2018). The GI value of rice shows a wide variation ranging from 48 to 92 , depending on the type of rice (Atkinson et al., 2008). Amylose has several active enzyme sites which are digested slowly. It is known that amylose is slowly digested because of its more linear compact physical structure. In contrast, amylopectin is digested and absorbed quickly because amylopectin has a branched structure, which has high glucose responses and a high glycemic index (GI) (Yang \& Lin, 2018). Rice is the most proper raw material for the manufacture of rice-based products as well as new cereal-based snacks, pre-cooked breakfast cereals, and modified starches including beverages because of its color, flavor, hypoallergenic, bland taste and better processing characteristics (Dalbhagat et al., 2019; Hagenimana et al., 2006).

Restructured rice, which is also called as artificial rice, is an effort to diversify main foods processed from carbohydratebased raw materials with the addition of certain substances to improve the quality of staple foods. Currently, there is a popular technology used to modify rice using an extrusion technology which is commonly called restructured rice or artificial rice. According to a research conducted by Patria et al. (2020) the production of restructured rice has disadvantages such as low physicochemical properties and cooking characteristics because of not adding any other ingredients. Mishra et al. (2012) reported that extrusion can be classified into two categories, namely cold extrusion and hot extrusion. According to Alavi et al. (2008) cold extrusion is a process similar to the one used for manufacturing pasta, and also produces a familiar shape which looks like milled rice. This technique does not utilize any additional thermal energy input other than the heat generated during the process itself and it mostly occurs in a low temperature (below $70^{\circ} \mathrm{C}$ ).

Porang (Amorphophallus mulleri B.) is a group of Araceae natives from Indonesia. Porang is one of glucomannan potential sources due to its high level of glucomannan content (Yanuriati et al., 2017). Glucomannan can slow down the absorption of sugar released from food and consequently reduces the increase in blood sugar level. Therefore, overall diabetes control can be improved in patients with diabetes by giving them a glucomannan-rich diet (Fang \& Wu, 2004). Calcium hydroxide or limestone is a rock formed from the skin of marine animals and alkaline solutions in starch with $\mathrm{pH} 11.8$ at $1 \% \mathrm{Ca}(\mathrm{OH})_{2}$ would ionize into $\mathrm{Ca}^{2+}$ and $\mathrm{OH}^{-}$, then it would form a cross-link with starch 
and glucomannan (Bryant \& Hamaker, 1997). Wang \& Johnson (2006) reported glucomannan has a unique characteristic in thermo-irreversible gels, where the solution does not form a gel because the acetyl group is blocking the glucomannan chain to interact with each other. However, the gel will be formed by heating at $85^{\circ} \mathrm{C}$ under weak alkali conditions with $\mathrm{pH}(9-10)$.

As far as we could possibly know, no such a study has been carried out wherein the development of restructured rice fortified with porang glucomannan has been attempted. Therefore, it is necessary to formulate the amount of water, $\mathrm{Ca}(\mathrm{OH})_{2}$, and PGM flour to restructure rice with good physical, chemical, cooking characteristics, and with a lower glycemic index.

\section{Materials and methods}

\subsection{Materials}

White rice japonica, TN-11 (Shuen Bau Factory, Pingtung, Taiwan), porang flour that contains glucomannan $69.75 \%$ (Ambico Co. Ltd., Indonesia), calcium hydroxide food grade (Showa Chemical Co. Ltd., Japan), xanthan gum (Gemfon Corporation, Taiwan), emulsifier sodium stearoyl lactate (SSL) (Sin Shen Cheng Factory, Taiwan), vegetable shortening (Wang Lai Store, Pingtung, Taiwan), pepsin from porcine gastric mucose (P7000, Sigma-Aldrich, St. Louis, MO, USA), $\alpha$-amylase from porcine pancreas (A3176, Sigma-Aldrich, St. Louis, MO, USA), amyloglucosidase from Aspergillus niger (A7095, Sigma-Aldrich, St. Louis, MO, USA), glucose oxidase-peroxidase kit GOPOD reagent enzymes (Megazyme International Ltd., Ireland), and D-glucose standard (Megazyme International Ltd., Ireland).

\subsection{Experimental design}

The optimization process was carried out by Central Composite Design (CCD) with Response Surface Methodology (RSM) using 6 center points (Wani \& Kumar, 2016a, b). Twenty experimental treatments were used to set up the experimental plan within -1 to +1 (coded levels) with variables of feed moisture (35-45\%), PGM (3\%-7\%), and $\mathrm{Ca}(\mathrm{OH})_{2}(0.04-0.1 \%)$. The responses used in this study were the WAI, WSI, whiteness, and hardness. The optimized restructured rice production results would be continued to analyze the chemical components, the 3D surface, the microstructure, the water absorption ratio (WAR), the cooking loss, the cooking time, and the eGI at the most optimum treatment point.

\subsection{Restructured rice preparation}

Restructured rice was prepared by following the modified protocols of Patria et al. (2020). First, Japonica rice variety TN-11 was grounded using small grinder (RT-04, Mill Powder Tech Co., Ltd., Taiwan) and sifted through an 80-mesh filter using sieve shakers (AS 200, RETSCH Ltd., Germany), then PGM (w/b, total dough basis) and $\mathrm{Ca}(\mathrm{OH})_{2}(\mathrm{w} / \mathrm{b}$, total dough basis) were added according to design, and emulsifier $1 \%(\mathrm{w} / \mathrm{b})$, shortening $2.5 \%(\mathrm{w} / \mathrm{b})$ and xanthan gum $1 \%(\mathrm{w} / \mathrm{b})$ were added based on the total dough.
After turning into a dough, it was put on the pasta extrusion machine (La Monferrina Model P6, Roma, Italy) with a die shaped like a rice $(2.22 \mathrm{~mm} \times 8.69 \mathrm{~mm})$ and the dough was cut off until becoming rice kernels. Then, the restructured rice were transferred into hot air and they were dried with a temperature of $40{ }^{\circ} \mathrm{C}$ for 2 hours.

\subsection{Water Absorption Index (WAI) and Water Soluble Index (WSI)}

The WAI and WSI of restructured rice were determined using the Equation 1 and 2, respectively, as outlined by Reshi et al. (2020):

WAI $(g / g)=\left[\frac{\text { Weight of gel }(\mathrm{g})}{\text { Weight of sample flour }(\mathrm{g})}\right]$

$\mathrm{WSI}(\%)=\left[\frac{\text { Weight of dried supernatant }(\mathrm{g})}{\text { Weight of sample flour }(\mathrm{g})} \times 100 \%\right]$

Where, the weight of gel represents the residue left over the removal of liquid portion and the supernatant represents the liquid portion that is separated from the residue after centrifugation.

\subsection{Color}

The color of the restructured rice sample was determined based on the procedure as described by Nielsen (2003) using a colorimeter (Color Quest XE, Hunter Lab, Inc., USA). The results of the analysis on whiteness was shown in the form of values L, a, b. Measurement of the total degree of color was used as a white base color. So, the whiteness can be calculated with the following Equation 3:

$\mathrm{W}=\left[100-\sqrt{(100-\mathrm{L})^{2}+\mathrm{a}^{2}+\mathrm{b}^{2}}\right]$

\subsection{Texture profile analysis}

The texture profile (hardness) analysis of restructured rice was modified based on Wang et al. (2013) using the Texture Profile Analyzer (5564, Instron Co., USA). Rice-shaped sample was compressed to $50 \%$ deformation. The plunger was withdrawn to the original height, and the sample was stopped for $5 \mathrm{~s}$, followed by the compression-withdraw cycle at $50 \%$ deformation. The speed of the compression head was adjusted to $30 \mathrm{~mm} / \mathrm{min}$ and the diameter probe was $3.09 \mathrm{~mm}$. The hardness value was the maximum peak force during the first compression.

\subsection{Proximate analysis}

The proximate analysis of nutrition composition was applied to the water, ash, carbohydrate, crude fat and crude protein using a method of Association of Official Analytical Chemists (2005), and then total dietary fiber (TDF) was modified using a method of DeVries et al. (1999). 


\subsection{Restructured rice surface and microstructure}

The $3 \mathrm{D}$ surface of the restructured rice was observed using a Laser Microscope (VK-X series, Keyence, USA) with $1.5 \mathrm{x}$ magnification. The microstructure of restructured rice was analyzed using the SEM (S-3000N, Hitachi High Technologies Co., Japan).

\subsection{Water Absorption Ratio (WAR), cooking losses, and cooking time}

The water absorption ratio and cooking losses during the cooking process were modified based on Kang et al. (2017). The sample ( $5 \mathrm{~g}$ ) was cooked into $20 \mathrm{~mL}$ boiling distilled water for 2-4 minutes. After the completion of the cooking process, the leached solids were removed and added into a petri dish for drying at $105{ }^{\circ} \mathrm{C}$. Simultaneously, the weight of cooked rice was taken accurately and its WAR was calculated. The dried leached solids were weighed and its cooking losses were noted. The WAR and the cooking losses can be determined by the Equations 4 and 5 as follows:

$$
\text { WAR }(\%)=\left[\frac{\text { Weight of cooked rice }- \text { Weight of dry rice }(\mathrm{g})}{\text { Weight of dry rice }(\mathrm{g})} \times 100 \%\right]
$$

Cooking Losses $(\%)=\left[\frac{\text { Weight of dried supernatant }(\mathrm{g})}{\text { Weight of dry rice }(\mathrm{g})} \times 100 \%\right]$

The cooking time of the samples was estimated using the method described by Singh et al. (2005).

\subsection{In vitro starch digestibility and estimated glycemic index (eGI)}

The rate of in vitro starch hydrolysis was analyzed by the method established by Goñi et al. (1997).

\subsection{Statistical analysis}

Data analysis was carried out using the Design Expert (DX) 7.1.5 program. The analysis results in the value of WAI, WSI, whiteness, and hardness of each restructured rice obtained in the treatment. The results of making optimal and validated restructured rice was analyzed in terms of the chemical components, the $3 \mathrm{D}$ surface, the microstructure, the cooking characteristics and the in vitro glycemic index evaluation. Later, it was compared with milled rice in the T-test statistics analysis using the SPSS version 22 software.

\section{Results and discussion}

\subsection{Optimization restructured rice}

The data of the WAI obtained ranged from $2.904 \mathrm{~g} / \mathrm{g}$ to $3.986 \mathrm{~g} / \mathrm{g}$. The determination of the model was based on a p-value of less than $5 \%$ (Table 1). The results of the model selection based on the number of squares of the sequential model among different models the quadratic model was suggested by DX 7.1.5 program
(Figure 1A). WAI can be used as a functional indicator to know the degree of the cooking of extruded products. Bryant et al. (2001) reported that if, the water is very important as a plasticizer in the extrusion process, it can reduce the degradation of rice starch and can increase the water absorption capacity of an extrudate. Meanwhile, Hagenimana et al. (2006) reported that at high temperature and low moisture, WAI decreased significantly due to dextrinization and gelatinization in rice analogues. This study showed that the WAI increased since it is caused by the presence of acetyl groups in glucomannan which is hydrophilic, so it can absorb large amounts of water.

The data of WSI ranged from $2.018 \%$ to $3.302 \%$. The determination of the model was based on a p-value of less than $5 \%$ (Table 1 ). The results of the model selection were based on the number of squares of the sequential model among different models, where the quadratic model was suggested by DX 7.1.5 program (Figure 1B). The water-soluble index determines the amount of free polysaccharide or polysaccharide released from the granule on the addition of excess water. High WSI values indicated the presence of dextrinized starch molecules. Onwulata et al. (2001) reported that higher water will cause a higher material flow rate in the barrel to reduce shear and starch degradation. Whereas, Stojceska et al. (2009) reported that lower water results in high starch degradation due to high shear and WSI showed that there was an increase in feed moisture content because of the lower degree of starch transformation and solubility of starch granules in water. The addition of PGM showed immense effect on WSI restructured rice. A higher content of glucomannan enhanced the WSI value as glucomannan is water soluble dietary fiber. Decrease in WSI was noticed because of interaction between hydrocolloids and water and also due to a reduced degree of gelatinization.

The whiteness index ranged from 72.83 to 85.02 . The determination of the model is based on a p-value of less than $5 \%$ (Table 1). The results of the model selection were based on the number of squares of the sequential model, among different models in the linear model suggested by DX 7.1.5 program (Figure 1C). The Color of the extruded product plays an important role in

Table 1. Estimated coefficients showing the significance of the linear, squared and interaction effects of extrusion conditions on the responses.

\begin{tabular}{ccccc}
\hline Parameters & WAI & WSI & Whiteness & Hardness \\
\hline $\mathrm{x}_{1}$ & 1.06 & 0.035 & 0.043 & 0.26 \\
$\mathrm{x}_{2}$ & 0.21 & 0.018 & 64.16 & 0.12 \\
$\mathrm{x}_{3}$ & 0.019 & 0.027 & 30.49 & 0.052 \\
$\mathrm{x}_{1} \cdot \mathrm{x}_{2}$ & 0.041 & $2.417 \mathrm{E}-003$ & - & $4.822 \mathrm{E}-005$ \\
$\mathrm{x}_{1} \cdot \mathrm{x}_{3}$ & $6.519 \mathrm{E}-003$ & $9.952 \mathrm{E}-004$ & - & $6.272 \mathrm{E}-007$ \\
$\mathrm{x}_{2} \cdot \mathrm{x}_{3}$ & $7.613 \mathrm{E}-003$ & $7.103 \mathrm{E}-004$ & - & 0.011 \\
$\mathrm{x}_{1}{ }^{2}$ & $2.478 \mathrm{E}-003$ & 1.41 & - & 6.11 \\
$\mathrm{x}_{2}{ }^{2}$ & 0.24 & 1.20 & - & 4.53 \\
$\mathrm{x}_{3}{ }^{2}$ & 0.17 & 1.00 & - & 3.51 \\
lack of fit & 0.1346 & 0.28 & 40.84 & 1.31 \\
$\mathrm{p}$ value & 0.0001 & 0.0008 & 0.0004 & 0.0016 \\
F value & 14.98 & 9.59 & 10.81 & 8.02 \\
\hline Significance at $\mathrm{p}<0.05 . \mathrm{x}_{1}:$ feed moisture content; $\mathrm{x}_{2}:$ porang glucomannan; $\mathrm{x}_{3}: \mathrm{Ca}(\mathrm{OH})_{2}$; \\
WAI: water absorption index; WSI: water solubility index.
\end{tabular}



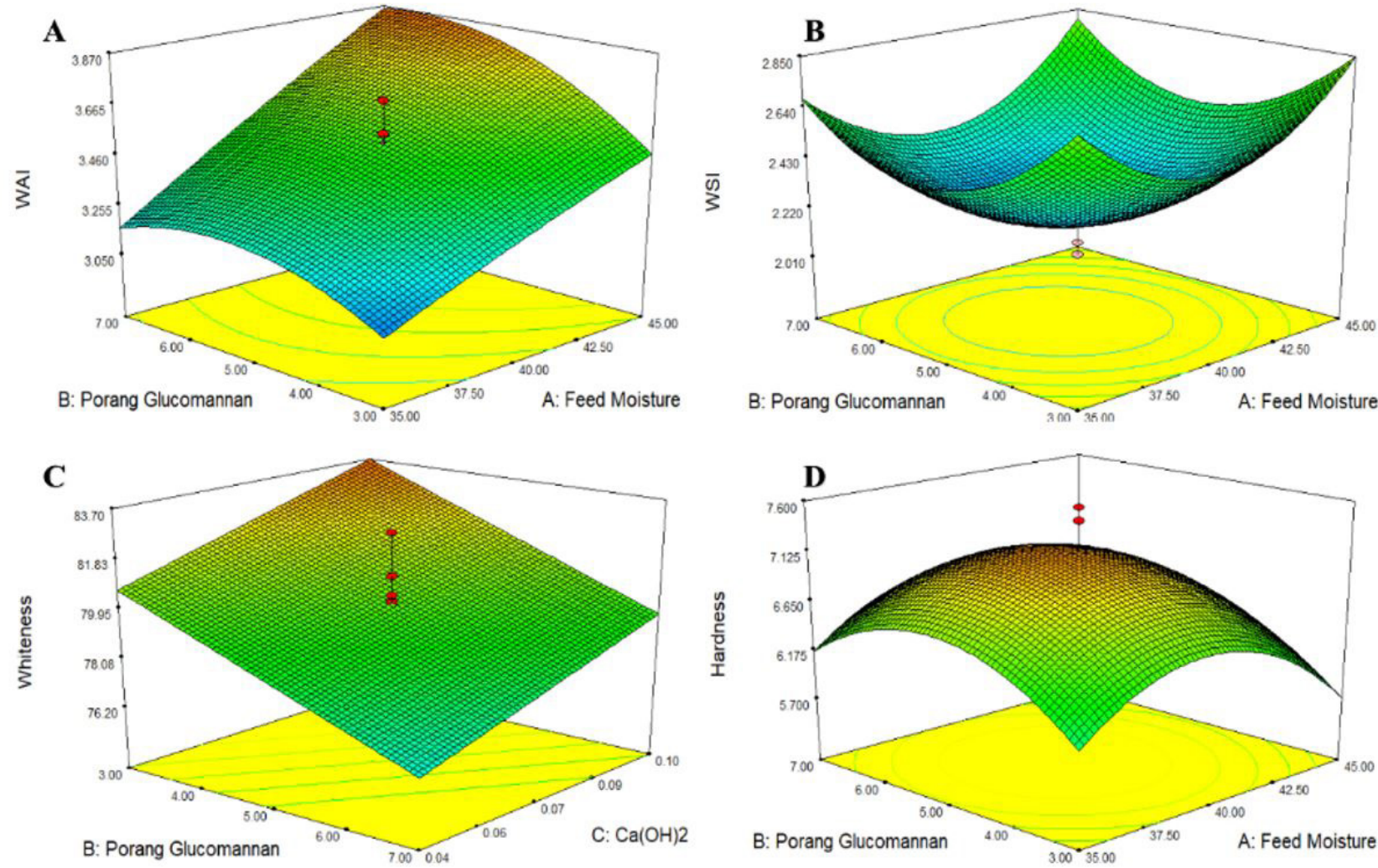

Figure 1. Response surface plot showing the interaction effect of extrusion processing variables on (A) WAI (B) WSI (C) Whiteness, and (D) Hardness.

consumer acceptance. The processing condition and composition of feed matrix greatly affected on Whiteness. This is due to the natural color of PGM (i.e. brown) so that, due to increase in the amount of PGM the whiteness was reduced simultaneously. The red color in porang flour is naturally found in porang tubers (Kurniawati \& Widjanarko, 2010). This is consistent with research conducted Xiong et al. (2009) on the making of surimi added glucomannan. The addition of glucomannan of more than $1 \%$ reduced the whiteness. Solo-de-Zaldivar et al. (2012) reported that higher the alkali content in konjac glucomannan (KGM), the greater the transparency of the gel would be.

The data on the hardness obtained ranged from 4.921 to 7.537. The determination of the model is based on a p-value of less than $5 \%$ (Table 1). The results of the model selection based on the number of squares of the sequential model, among different models, the quadratic model was suggested by DX 7.1.5 program (Figure 1D). The hardness is the peak force required for a probe or parallel blades to penetrate the extrudate. The higher the value, the maximum peak force is required to breakdown the sample. The following research conducted by Kantrong et al. (2018) showed that the higher feed moisture content would make the extrudate dense result in greater hardness, and also the effect of adding PGM and $\mathrm{Ca}(\mathrm{OH})_{2}$, will increase the hardness of analog rice due to the cross-linking of $\mathrm{Ca}^{++}$ with $\mathrm{OH}^{-}$groups in starch or glucomannan. The result obtained was similar to that found by Zazueta-Morales et al. (2001) showing that the increase in penetration force and calcium hydroxide due to formation of bond between calcium ions and $\mathrm{OH}$ group of starch leads to the production of strong product with greater hardness. Huang et al. (2007) reported that it was well-known that konjac glucomannan has extremely high viscosity and water holding capacity, so there is a slight increase in hardness.

\subsection{Validation data of optimum conditions}

Validation was carried out by applying the optimum solution results from the program that was predicted in production of restructured rice using factors like feed moisture, $\mathrm{PGM}$, and $\mathrm{Ca}(\mathrm{OH})_{2} 41.27 \%$, $5.01 \%$ and $0.08 \%$ respectively with desirability value 0.724 . Table 2 shows the prediction results from the optimum solution point of the WAI, the WSI, the whiteness, and the hardness. The difference in the response value of the WAI, WSI, whiteness, and hardness was predicted at $2.56 \%, 1.81 \%, 0.37 \%$, and $0.51 \%$ respectively.

\subsection{Characterization and evaluation of optimum restructured rice}

\section{Chemical components}

The carbohydrate content in restructured rice was significantly lower $(\mathrm{p}<0.05)$ compared to milled rice, where the value of restructured rice was $76.75 \%$, while milled rice $78.63 \%$ (Table 3 ). During the production of restructured rice, the carbohydrate value was lower because of the use of shortening and calcium 
hydroxide. Low carbohydrates in restructured rice are very suitable for the prevention of obesity and diabetes. According to Wolever et al. (1990) lower carbohydrate levels results in improving of the blood glucose level in insulin-dependent diabetes (type 1) and non-insulin-dependent diabetes (type 2).

Crude protein content in restructured rice was significantly lower $(\mathrm{p}<0.05)$ than milled rice, the protein value in restructured rice was $5.82 \%$ while in milled rice $7.12 \%$ (Table 3 ). This is due to some additions of PGM, $\mathrm{Ca}(\mathrm{OH})_{2}$, xanthan gum, emulsifier, and shortening used in making restructured rice so that, the protein in the raw material is replaced. Therefore, it is directly proportional to protein content i.e. higher protein content of the raw material results in the final product with greater protein content and vice versa (Noviasari et al., 2013). The standard of protein content in milled rice generally ranges from $5-8 \%$ (Gebhardt et al., 2008).

Crude fat content in restructured rice was significantly higher $(\mathrm{p}<0.05)$ than milled rice, the fat value in restructured rice was $2.92 \%$ while in milled rice $0.68 \%$ (Table 3 ). The fat content is higher in analog rice because of the addition of shortening in the dough before it is extruded. The addition of shortening makes it easier to avoid stacking on the screw during the extrusion process. The oil is essential to avoid adhesions during extrusion and to produce analog rice with fine surface. Fat can reduce the frictional force between particles and surface of the screw and barrel (Assoud \& Kleinke, 2005).

Ash content in restructured rice was significantly higher $(\mathrm{p}<0.05)$ than that in milled rice, the fat value in restructured rice was $0.64 \%$ while in milled rice $0.43 \%$ (Table 3 ). Ash content in restructured rice was higher than that in milled rice due to the addition of calcium and PGM, which has enough ash content. The mineral content in restructured rice is affected by raw materials which contain different types and levels of minerals. The increase in mineral content in this study was caused by the reduced moisture level, that leads to enhance the other nutrients (Kumoro \& Noprastika, 2017).

Water content is an important parameter of food products because the water content in food determines the acceptability and freshness of food. Water existing in the material can affect the appearance, texture, taste, shelf life, and quality and durability of the material (Winarno, 2002). Based on the results, water content of restructured rice was significantly higher $(\mathrm{p}<0.05)$ than that in milled rice. Water content of restructured rice was $13.87 \%$ while the water content of ground rice was $13.14 \%$ (Table 3 ). The level of water content in restructured rice was influenced by material formula, extrusion temperature, and the drying process performed after the extrusion process.
Total dietary fiber (TDF) in restructured rice was significantly higher $(p<0.05)$ than that in milled rice, the value of restructured rice was $10.69 \%$ while that in milled rice $0.36 \%$ (Table 3 ). TDF levels in restructured rice were higher than those in milled rice due to the addition of raw materials which are rich in dietary fiber such as PGM and xanthan gum. Health agencies have also approved claims related to fiber and glycaemia control and other polysaccharide complexes (Goff et al., 2018).

\section{Surface and microstructure}

It can be seen that the $3 \mathrm{D}$ surface of optimum restructured rice with PGM (Figure 2B) is very similar to milled rice (Figure 2A) where it seems to have a smooth surface and looks like a convex shape. This is due to the addition of PGM and $\mathrm{Ca}(\mathrm{OH})_{2}$ and the pre gelatinization treatment during extrusion process. Whereas, in the restructured rice without PGM (Figure 2C) there are many perforations which are not similar to milled rice. Patria et al. (2020) reported that the pre gelatinization treatment in the making of restructured rice can make the surface soft and sturdier and the research conducted by Liu et al. (2013) showed the combination of adding konjac glucomannan with the heating on making surimi has shown to increase the strength of the gel so that it is not easy to break.

The microstructure of the restructured rice after the extruding process and the milled rice is shown in Figure 3A and $3 \mathrm{~B}$, and the gel structure after being cooked was presented in Figure 3C and 3D. Glucomannan binds starch during the partial gelatinization and the partially gelatinized restructured rice is caused by the use of hot water in the preparation of the dough and the pressure during the extrusion process. Heating and compression during the extrusion process can cause the gelatinization either partially or completely (Mishra et al., 2012). Furthermore, components that interact one with each other lead to compact structure. The microstructure of restructured rice is more compact compared to that of the original rice. The structure of post-extruded rice analogs was

Table 3. Chemical components of optimum restructured rice and milled rice.

\begin{tabular}{cccr}
\hline No & Parameters (\%) & $\begin{array}{c}\text { Optimum } \\
\text { Restructured rice }\end{array}$ & Milled Rice \\
\hline 1 & Carbohydrate & $76.75 \pm 0.12^{\mathrm{a}}$ & $78.63 \pm 0.09^{\mathrm{b}}$ \\
2 & Crude Protein & $5.82 \pm 0.03^{\mathrm{a}}$ & $7.12 \pm 0.12^{\mathrm{b}}$ \\
3 & Crude Fat & $2.92 \pm 0.09^{\mathrm{a}}$ & $0.68 \pm 0.07^{\mathrm{b}}$ \\
4 & Ash & $0.64 \pm 0.01^{\mathrm{a}}$ & $0.43 \pm 0.01^{\mathrm{b}}$ \\
5 & Water & $13.87 \pm 0.09^{\mathrm{a}}$ & $13.14 \pm 0.12^{\mathrm{b}}$ \\
6 & Total Dietary Fiber & $10.69 \pm 0.02^{\mathrm{a}}$ & $0.36 \pm 0.14^{\mathrm{b}}$ \\
\hline \multicolumn{4}{l}{ Different notations on the same line show differences at $\alpha=0.05(5 \%)}$.
\end{tabular}

Table 2. Predicted and experimental values of the responses at the optimum conditions.

\begin{tabular}{lcccc}
\hline & & \multicolumn{3}{c}{ Response } \\
\cline { 2 - 5 } & WAI (g/g) & WSI (\%) & Whiteness & Hardness (kgf) \\
\hline Prediction & 3.601 & 2.218 & 80.41 & 7.047 \\
Validation & 3.697 & 2.259 & 80.71 & 7.083 \\
Coefficient of Value (\%) & 2.56 & 1.81 & 0.37 & 0.51 \\
\hline
\end{tabular}


influenced by feed moisture in the formula of the extrudates. The water serves as a plasticizer agent for starch material and it can reduce viscosity and mechanical energy, as well as it inhibits the formation of bubbles, resulting in a dense product (Assoud \& Kleinke, 2005). Identically, small-sized nanopores within the structure increase the resistance to deform whereas, nanopores of large size are attributed to stretching and rupturing of the sheets (Zhou et al., 2013).

The development of a micro post-cooking gel occurs due to the presence of water and heating. Gel develops in restructured rice that is different from the gel obtained by milled rice. Restructured rice after being cooked for $3 \mathrm{~min}$ showed that it was gelatinized
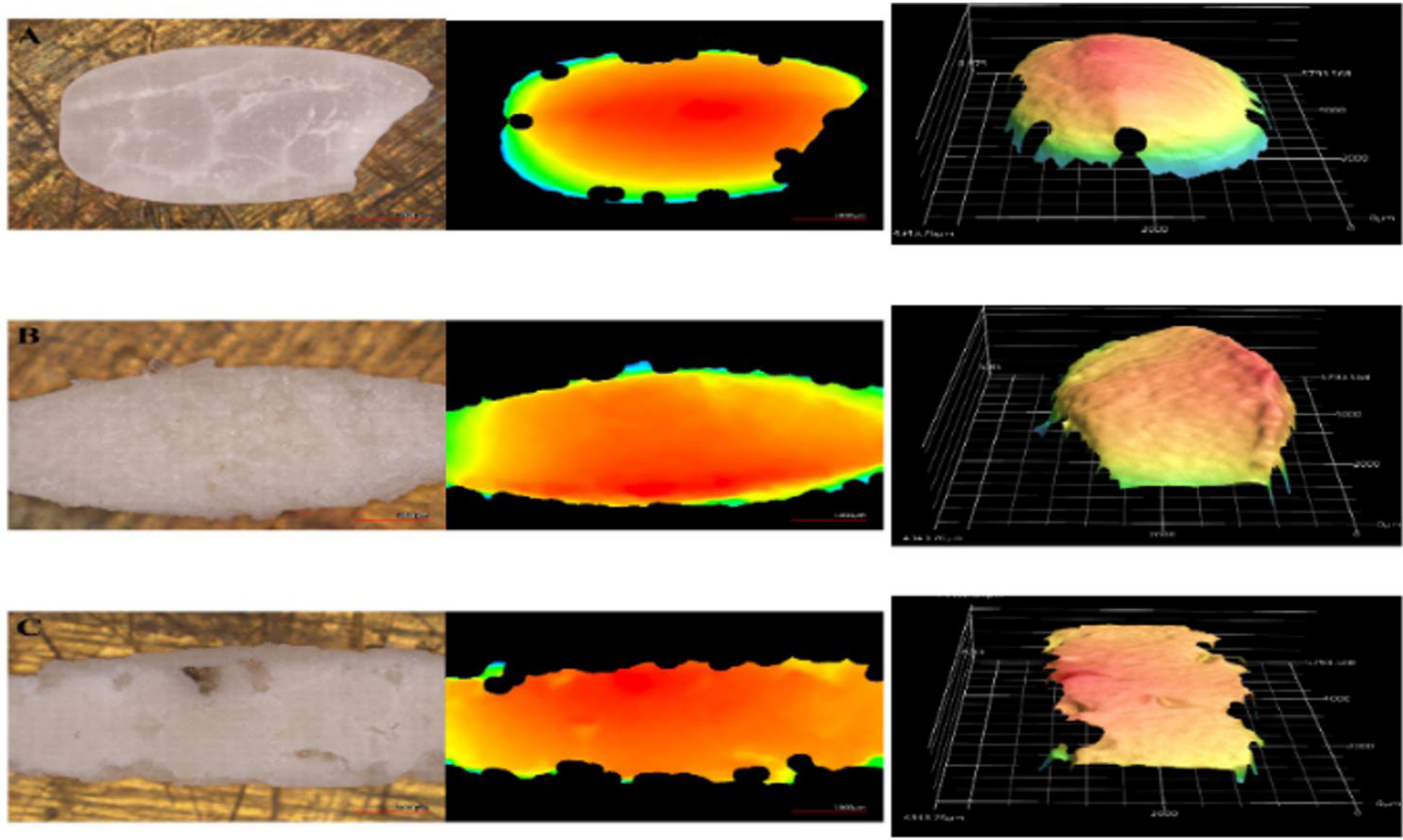

Figure 2. Surface of (A) dry milled rice (B) optimum restructured rice with PGM (C) restructured rice without PGM.
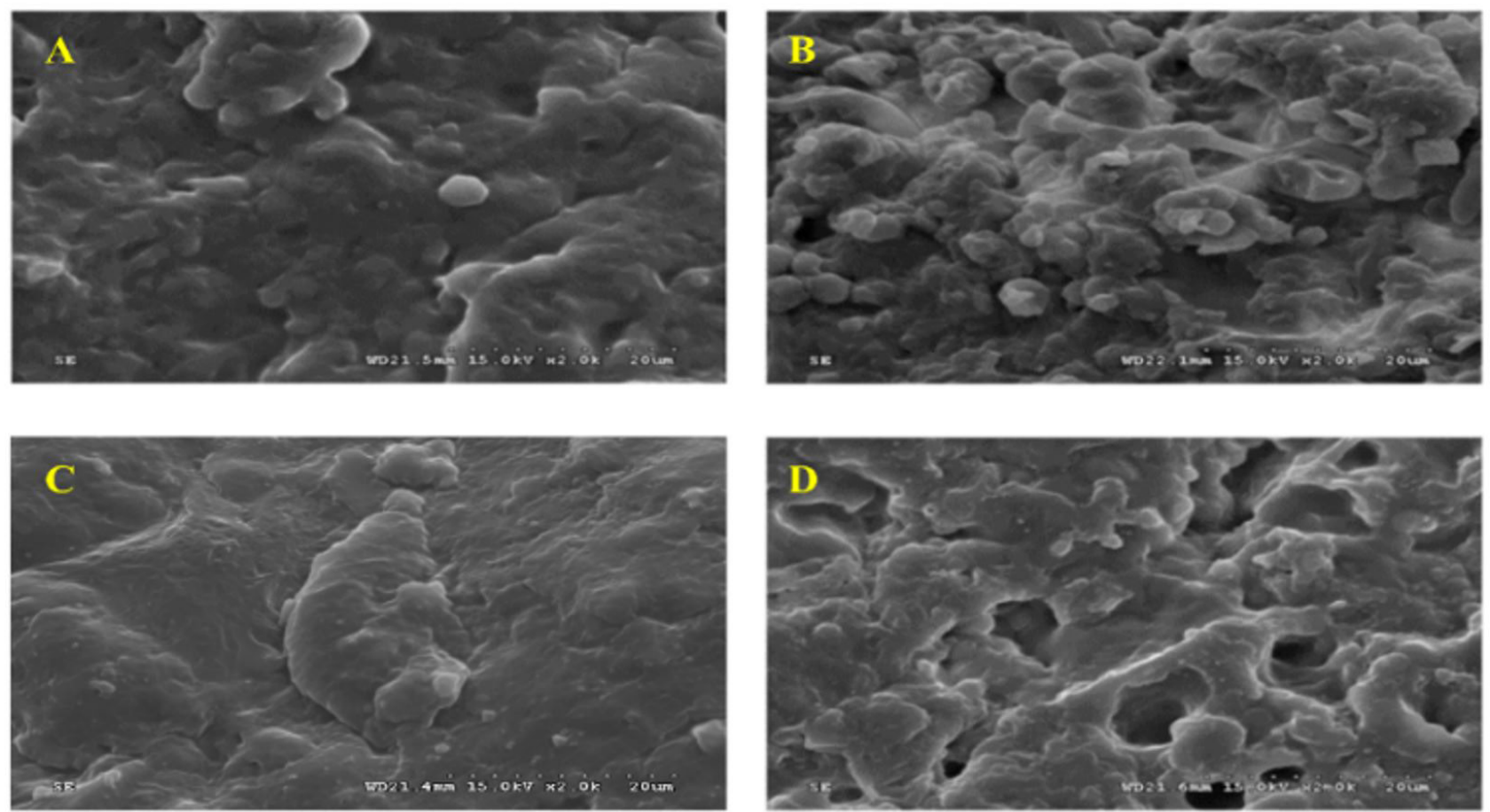

Figure 3. Microstructure of (A) dry optimum restructured rice (B) dry milled rice (C) cooked optimum restructured rice and (D) cooked milled rice. 
properly. It can be seen from the microstructure in the cooked restructured rice which looks softer and has no pores.

\section{Cooking characteristics}

Water absorption ratio (WAR) in restructured rice was significantly higher $(\mathrm{p}<0.05)$ compared to that milled rice and restructured rice without PGM, and the value of restructured rice was $201.21 \%$ while that in milled rice was $113.83 \%$ and that in restructured rice without PGM was $152.78 \%$ (Table 4). The WAR percentage in the extruded optimum restructured rice shows the level of hydration which may affect the eating quality. The rehydration value for extruded restructured fortified rice was consistent with rehydration capacity. The value of restructured rice was higher because of the effect of glucomannan which is hydrocolloid or that can bind to large amounts of water compared to starch. WAR depends on the availability of hydrophilic groups which bind water molecules and on the gel-forming capacity of macromolecules.

Cooking losses in restructured rice was significantly higher $(\mathrm{p}<0.05)$ than those in milled rice, the cooking losses value in restructured rice was $4.99 \%$ while those in milled rice were $1.67 \%$ and in restructured rice without PGM were 1.75\% (Table 4). Cooking losses value in optimum restructured rice was higher because optimum restructured rice is partially gelatinized, because some polysaccharide losses when it is cooked and it is also the effect of adding glucomannan which is certainly water-soluble, so that some glucomannan which is not bound well with starch will be losses when it is cooked. L. Wang et al. (2016) stated that during extrusion process, the temperature and the screw speed affects the quality and texture of brown rice pasta and also (Zhao et al., 2017) reported that when greater konjac glucomannan (KGM) was substituted with wheat flour, dough mixing increased the cooking loss of noodle samples, suggesting that a greater amount of exudates escaped from the dough system during starch granule gelatinization.

Cooking time in restructured rice was significantly lower $(\mathrm{p}<0.05)$ than that in milled rice, the cooking time value in restructured rice was $5.1 \mathrm{~min}$ while that milled rice was $10.5 \mathrm{~min}$, and that restructured rice without PGM was 4.7 min (Table 4). Cooking time on restructured rice was lower because of the gelatinization process in the extrusion process so that the cooking time should be quick and increase in feed water content increases the cooking time of restructured rice. Processing parameters such as feed moisture and barrel temperature can indirectly contribute to cooking time. Sukamto \& Patria (2020) reported that the cooking time of analog rice products was greatly influenced by the temperature of gelatinization that occurred in the used material.

\section{Hydrolysis Index (HI) and Estimated Glycemic Index (eGI)}

The hydrolysis index was shown in (Figure 4) and kinetic constant $(\mathrm{K}), \mathrm{C} \infty$, and $\mathrm{HI}$ are shown in Table 5 . On the graph, it can be seen that the lowest hydrolysis starch value is restructured rice fortified with PGM. Glucomannan can inhibit starch retrogradation because it acts as a physical barrier that prevents amylopectin chain linkages. (Charoenrein et al., 2011; Park et al., 2019) reported if the steaming process or the process of drying using hot air during production of instant noodles can cause strong interactions between dissolved amylose and glucomannan and this delays enzymatic digestion.

The estimated glycemic index of restructured rice with PGM was significantly lower $(\mathrm{p}<0.05)$ compared to milled rice and restructured rice without PGM. The value of restructured rice with PGM was 68.23, milled rice 79.34, and restructured rice without PGM 76.73. The GI value of optimum restructured rice was 68.23 which means that it is classified as a medium GI. The medium GI value in restructured rice with PGM is certainly due to the addition of PGM. According to Jenkins et al. (2008), foods with GI classified as $<55$ is low, $56-69$ is medium, and 70>

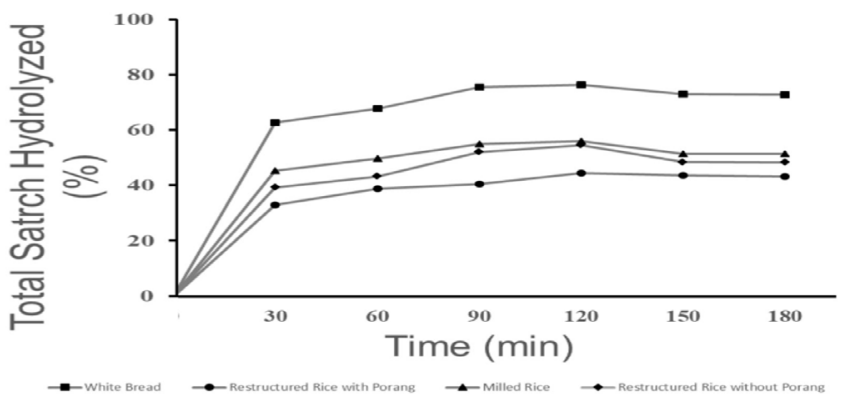

Figure 4. In vitro starch hydrolysis.

Table 4. Cooking characteristics of optimum restructured rice and milled rice.

\begin{tabular}{cccrc}
\hline No & Parameters & Optimum Restructured Rice & Milled Rice & Restructured Rice without PGM $^{*}$ \\
\hline 1 & Water Absorption Ratio (\%) & $201.21 \pm 0.98^{\mathrm{a}}$ & $113.83 \pm 0.14^{\mathrm{c}}$ & $152.78 \pm 0.12^{\mathrm{b}}$ \\
2 & Cooking Losses (\%) & $4.99 \pm 0.24^{\mathrm{a}}$ & $1.67 \pm 0.20^{\mathrm{c}}$ & $1.75 \pm 0.07^{\mathrm{bc}}$ \\
3 & Cooking Time (min) & $5.1 \pm 0.28^{\mathrm{b}}$ & $10.5 \pm 0.50^{\mathrm{a}}$ & $4.7 \pm 0.71^{\mathrm{c}}$ \\
\hline${ }^{*}$ & &
\end{tabular}

${ }^{*}$ Patria et al. (2020). Different notations on the same line show differences at $\alpha=0.05(5 \%)$.

Table 5. Concentration at a time $(\mathrm{C})$, concentration equilibrium $(\mathrm{C} \infty)$, kinetic constant $(\mathrm{K})$, hydrolysis index $(\mathrm{HI})$.

\begin{tabular}{|c|c|c|c|c|c|c|}
\hline No & Sample & $\mathrm{C}_{90}$ & $\mathrm{C} \infty$ & K & $\mathrm{HI}$ & eGI \\
\hline 1 & Restructured Rice with PGM & $40.67^{c}$ & $44.77^{\mathrm{c}}$ & $0.0265 \pm 0.00022^{c}$ & $51.956 \pm 0.131^{\mathrm{c}}$ & $68.23^{\mathrm{c}}$ \\
\hline 2 & Milled Rice & $55.27^{\mathrm{a}}$ & $56.29^{\mathrm{a}}$ & $0.0443 \pm 0.00022^{\mathrm{a}}$ & $72.178 \pm 0.071^{\mathrm{a}}$ & $79.34^{\mathrm{a}}$ \\
\hline 3 & Restructured Rice without PGM & $52.37^{\mathrm{b}}$ & $54.85^{\mathrm{b}}$ & $0.0344 \pm 0.00030^{\mathrm{b}}$ & $67.440 \pm 0.132^{\mathrm{b}}$ & $76.73^{\mathrm{b}}$ \\
\hline
\end{tabular}

Different notations on the same column show differences at $\alpha=0.05(5 \%)$. $\mathrm{C}_{90}$ means the concentration at the $90^{\text {th }}$ minute. 
is high. The estimated glycemic index in optimum restructured rice has a lower value than that in the milled rice, because of the addition of PGM, glucomannan compounds in restructured rice are resistant to hydrolyzing into glucose by digestive enzymes. Matsuura (1998) reported that glucomannan is resistant to hydrolysis by digestive enzymes, so it's only minimally digested in small intestine. Although, small amounts of these products may be absorbed from the large intestine, most of it is excreted in the feces along with some undigested glucomannan. Soluble dietary fiber in general and konjac fiber in particular has a beneficial effect on serum glucose levels and this effect may be caused by delayed gastric emptying and delayed glucose dispersion in the intestinal lumen. KGM can delay gastric emptying by modulating the rate of absorption of nutrients from the small intestine with increased insulin sensitivity (Vuksan et al., 2001).

\section{Conclusion}

Optimization restructured rice production fortified with porang glucomannan using a pasta extruder showed that the treatment of the optimization production significantly affects the WAI, WSI, Hardness, and Whiteness. T-Test results showed that the chemical components, cooking characteristics of optimum restructured rice compared with those of milled rice gave significant differences in terms of WAR, cooking losses, cooking time, and eGI. In further studies, it is suggested to conduct sensory analysis and it is expected that the restructured rice can be implemented, commercialized, and consumed by the entire world population to prevent obesity and diabetes mellitus.

\section{References}

Alavi, S., Bugusu, B., Cramer, G., Dary, O., Lee, T.-C., Martin, L., \& Wailes, E. (2008). Rice fortification in developing countries: a critical review of the technical and economic feasibility. Washington: Institute of Food Technologists.

Amin, T., Naik, H., Hussain, S. Z., Rather, A., Murtaza, I., \& Dar, B. (2017). Structural properties of high-protein, low glycaemic index (GI) rice flour. International Journal of Food Properties, 20(11), 2793-2804. http://dx.doi.org/10.1080/10942912.2016.1252391.

Association of Official Analytical Chemists - AOAC. (2005). Official methods of analysis of AOAC. Washington: AOAC.

Assoud, A., \& Kleinke, H. (2005). Unique barium selenostannateselenide: $\mathrm{Ba}_{7} \mathrm{Sn}_{3} \mathrm{Se}_{13}$ (and its variants $\mathrm{Ba}_{7} \mathrm{Sn}_{3} \mathrm{Se}_{13}{ }_{\delta} \mathrm{Te}_{\delta}$ ) with $\mathrm{SnSe} 4$ tetrahedra and isolated Se anions. Chemistry of Materials, 17(17), 4509-4513. http://dx.doi.org/10.1021/cm050787y.

Atkinson, F. S., Foster-Powell, K., \& Brand-Miller, J. C. (2008). International tables of glycemic index and glycemic load values: 2008. Diabetes Care, 31(12), 2281-2283. http://dx.doi.org/10.2337/ dc08-1239. PMid:18835944.

Bryant, C. M., \& Hamaker, B. R. (1997). Effect of lime on gelatinization of corn flour and starch. Cereal Chemistry, 74(2), 171-175. http:// dx.doi.org/10.1094/CCHEM.1997.74.2.171.

Bryant, R. J., Kadan, R. S., Champagne, E. T., Vinyard, B. T., \& Boykin, D. (2001). Functional and digestive characteristics of extruded rice flour. Cereal Chemistry, 78(2), 131-137. http://dx.doi.org/10.1094/ CCHEM.2001.78.2.131.

Charoenrein, S., Tatirat, O., Rengsutthi, K., \& Thongngam, M. (2011). Effect of konjac glucomannan on syneresis, textural properties and the microstructure of frozen rice starch gels. Carbohydrate Polymers, 83(1), 291-296. http://dx.doi.org/10.1016/j. carbpol.2010.07.056.

Dalbhagat, C. G., Mahato, D. K., \& Mishra, H. N. (2019). Effect of extrusion processing on physicochemical, functional and nutritional characteristics of rice and rice-based products: a review. Trends in Food Science \& Technology, 85, 226-240. http://dx.doi.org/10.1016/j. tifs.2019.01.001.

DeVries, J., Prosky, L., Li, B., \& Cho, S. (1999). A historical perspective on defining dietary fiber. Cereal Foods World, 44, 367-369. Retrieved from https://www.cerealsgrains.org/initiatives/definitions/Documents/ DietaryFiber/DFHistory.pdf

Fang, W., \& Wu, P. (2004). Variations of konjac glucomannan (KGM) from Amorphophallus konjac and its refined powder in China. Food Hydrocolloids, 18(1), 167-170. http://dx.doi.org/10.1016/ S0268-005X(03)00044-4.

Gebhardt, S., Cutrufelli, R., Howe, J., Haytowitz, D., Pehrsson, P., Lemar, L., Holcomb, G., Nickle, M., Thomas, R., Exler, J., Showell, B., \& Holden, J. (2008). USDA national nutrient database for standard reference, release 21. Washington: Agricultural Research Service, United States Department of Agriculture. Retrieved from https://www.ars.usda. gov/research/publications/publication/?seqNo115=199178

Goff, H. D., Repin, N., Fabek, H., El Khoury, D., \& Gidley, M. J. (2018). Dietary fibre for glycaemia control: towards a mechanistic understanding. Bioactive Carbohydrates and Dietary Fibre, 14, 3953. http://dx.doi.org/10.1016/j.bcdf.2017.07.005.

Goñi, I., Garcia-Alonso, A., \& Saura-Calixto, F. (1997). A starch hydrolysis procedure to estimate glycemic index. Nutrition Research (New York, N.Y.), 17(3), 427-437. http://dx.doi.org/10.1016/S02715317(97)00010-9.

Hagenimana, A., Ding, X., \& Fang, T. (2006). Evaluation of rice flour modified by extrusion cooking. Journal of Cereal Science, 43(1), 38-46. http://dx.doi.org/10.1016/j.jcs.2005.09.003.

Huang, M., Kennedy, J., Li, B., Xu, X., \& Xie, B. (2007). Characters of rice starch gel modified by gellan, carrageenan, and glucomannan: a texture profile analysis study. Carbohydrate Polymers, 69(3), 411418. http://dx.doi.org/10.1016/j.carbpol.2006.12.025.

Jenkins, D. J., Kendall, C. W., Nguyen, T. H., Marchie, A., Faulkner, D. A., Ireland, C., Josse, A. R., Vidgen, E., Trautwein, E. A., Lapsley, K. G., Holmes, C., Josse, R. G., Leiter, L. A., Connelly, P. W., \& Singer, W. (2008). Effect of plant sterols in combination with other cholesterollowering foods. Metabolism: Clinical and Experimental, 57(1), 130-139. http://dx.doi.org/10.1016/j.metabol.2007.08.016. PMid:18078870.

Kang, J., Lee, J., Choi, M., Jin, Y., Chang, D., Chang, Y. H., Kim, M., Jeong, Y., \& Lee, Y. (2017). Physicochemical and textural properties of noodles prepared from different potato varieties. Preventive Nutrition and Food Science, 22(3), 246-250. PMid:29043225.

Kantrong, H., Charunuch, C., Limsangouan, N., \& Pengpinit, W. (2018). Influence of process parameters on physical properties and specific mechanical energy of healthy mushroom-rice snacks and optimization of extrusion process parameters using response surface methodology. Journal of Food Science and Technology, 55(9), $3462-$ 3472. http://dx.doi.org/10.1007/s13197-018-3271-2. PMid:30150805.

Kumar, A., Sahoo, S., Sahu, S., Nayak, L., Ngangkham, U., Parameswaran, C., Bose, L. K., Samantaray, S., Kumar, G., \& Sharma, S. G. (2018). Rice with pulses or cooking oils can be used to elicit lower glycemic response. Journal of Food Composition and Analysis, 71, 1-7. http:// dx.doi.org/10.1016/j.jfca.2018.05.003.

Kumoro, A. C., \& Noprastika, I. (2017). Proximate composition and gelatinization properties of rice analogues from breadfruit, mung bean and carrot flours at various dough compositions and drying time. Carpathian Journal of Food Science \& Technology, 9(3). Retrieved from https://pdfs.semanticscholar. 
org/196c/fcd8550506ac98cdad0dc05cb28f5bd83023.pdf?_ $\mathrm{ga}=2.115114309 .338731747 .1593588813-1561389346.1588608551$

Kurniawati, A. D., \& Widjanarko, S. B. (2010). Effects of multiple ethanol leaching with difference concentration on physichal and chemical properties of porang flour (Amorphophallus oncophyllus). Malang: Universitas Brawijaya. Retrieved from https://www.researchgate.net/ profile/Adelya_Kurniawati/publication/305983998_PENGARUH_ TINGKAT_PENCUCIAN_DAN_LAMA_KONTAK_DENGAN_ ETANOL_TERHADAP_SIFAT_FISIK_DAN_KIMIA_TEPUNG_ PORANG_Amorphophallus_oncophyllus_Effects_of_Multiple_ Ethanol_Leaching_with_Difference_Concentration_on_P/ links/57a80e4908ae3f45293940c9.pdf

Liu, J., Wang, X., \& Ding, Y. (2013). Optimization of adding konjac glucomannan to improve gel properties of low-quality surimi. Carbohydrate Polymers, 92(1), 484-489. http://dx.doi.org/10.1016/j. carbpol.2012.08.096. PMid:23218324.

Matsuura, Y. (1998). Degradation of konjac glucomannan by enzymes in human feces and formation of short-chain fatty acids by intestinal anaerobic bacteria. Journal of Nutritional Science and Vitaminology, 44(3), 423-436. http://dx.doi.org/10.3177/jnsv.44.423. PMid:9742462.

Mishra, A., Mishra, H. N., \& Srinivasa Rao, P. (2012). Preparation of rice analogues using extrusion technology. International Journal of Food Science \& Technology, 47(9), 1789-1797. http://dx.doi. org/10.1111/j.1365-2621.2012.03035.x.

Mohanty, S. (2013). Trends in global rice consumption. Rice Today, $12(1), 44-45$.

Nielsen, S. (2003). Food analysis (3rd ed.). New York: Plenum Publisher.

Noviasari, S., Kusnandar, F., \& Budijanto, S. (2013). Development of white corn-based rice analogues. Jurnal Teknologi dan Industri Pangan, 24(2), 194-200. http://dx.doi.org/10.6066/ jtip.2013.24.2.194.

Onwulata, C., Smith, P., Konstance, R., \& Holsinger, V. (2001). Incorporation of whey products in extruded corn, potato or rice snacks. Food Research International, 34(8), 679-687. http://dx.doi. org/10.1016/S0963-9969(01)00088-6.

Park, E. Y., Kim, H. Y., Shin, H. Y., Jeon, Y. I., Kim, J. M., Kim, S., \& Kim, J. Y. (2019). Change in textural properties, starch digestibility, and aroma of nonfried instant noodles by substitution of konjac glucomannan. Cereal Chemistry, 96(4), 784-791. http://dx.doi. org/10.1002/cche.10180.

Patria, D. G., Sutrisno, A., Hsu, J.-L., \& Lin, J. (2020). Physical properties and cooking quality of extruded restructured rice: impact of water temperature and water level. Food Research, 4(5), 1616-1622. http:// dx.doi.org/10.26656/fr.2017.4(5).141.

Reshi, M., Shafiq, F., Hussain, S. Z., Naseer, B., \& Amin, T. (2020). Physicochemical properties of iron-fortified, low glycemic index (GI) barley based extruded ready-to-eat snacks developed using twin-screw extruder. Journal of Food Processing and Preservation, 44(8), e14606. http://dx.doi.org/10.1111/jfpp.14606.

Singh, N., Kaur, L., Singh Sodhi, N., \& Singh Sekhon, K. (2005). Physicochemical, cooking and textural properties of milled rice from different Indian rice cultivars. Food Chemistry, 89(2), 253-259. http://dx.doi.org/10.1016/j.foodchem.2004.02.032.

Solo-de-Zaldivar, B., Herranz, B., \& Borderias, J. (2012). First steps in using glucomannan to make thermostable gels for potential use in mince fish reestructuration. International Journal of Food Engineering, 8(1). http://dx.doi.org/10.1515/1556-3758.2407.

Stojceska, V., Ainsworth, P., Plunkett, A., \& İbanoğlu, Ş. (2009). The effect of extrusion cooking using different water feed rates on the quality of ready-to-eat snacks made from food by-products. Food Chemistry, 114(1), 226-232. http://dx.doi.org/10.1016/j.foodchem.2008.09.043.
Sukamto, S., \& Patria, D. G. (2020). The utilization of flour made of the non-milled rice as analog rice ingredients. Food Research, 4(5), 1427-1434. http://dx.doi.org/10.26656/fr.2017.4(5).108.

Vuksan, V., Sievenpiper, J. L., Xu, Z., Wong, E. Y., Jenkins, A. L., BeljanZdravkovic, U., Leiter, L. A., Josse, R. G., \& Stavro, M. P. (2001). Konjac-Mannan and American ginsing: emerging alternative therapies for type 2 diabetes mellitus. Journal of the American College of Nutrition, 20(5, Suppl 5), 370S-380S. http://dx.doi.org/10.1080/ 07315724.2001.10719170. PMid:11603646.

Wang, J. P., An, H. Z., Jin, Z. Y., Xie, Z. J., Zhuang, H. N., \& Kim, J. M. (2013). Emulsifiers and thickeners on extrusion-cooked instant rice product. Journal of Food Science and Technology, 50(4), 655-666. http://dx.doi.org/10.1007/s13197-011-0400-6. PMid:24425967.

Wang, L., Duan, W., Zhou, S., Qian, H., Zhang, H., \& Qi, X. (2016). Effects of extrusion conditions on the extrusion responses and the quality of brown rice pasta. Food Chemistry, 204, 320-325. http:// dx.doi.org/10.1016/j.foodchem.2016.02.053. PMid:26988508.

Wang, W., \& Johnson, A. (2006). Konjac introduction. Cyber Colloids. Retrieved from http://www.cybercolloids.net/information/technicalarticles/introduction-konjac

Wani, S. A., \& Kumar, P. (2016a). Development and parameter optimization of health promising extrudate based on fenugreek oat and pea. Food Bioscience, 14, 34-40. http://dx.doi.org/10.1016/j. fbio.2016.02.002.

Wani, S., \& Kumar, P. (2016b). Fenugreek enriched extruded product: optimization of ingredients using response surface methodology. International Food Research Journal, 23(1), 18.

Winarno, F. (2002). Kimia Pangan dan gizi. Jakarta: Gramedia Pustaka Utama.

Wolever, T. M., Jenkins, D. J., Vuksan, V., Josse, R. G., Wong, G. S., \& Jenkins, A. L. (1990). Glycemic index of foods in individual subjects. Diabetes Care, 13(2), 126-132. http://dx.doi.org/10.2337/ diacare.13.2.126. PMid:2351011.

Xiong, G., Cheng, W., Ye, L., Du, X., Zhou, M., Lin, R., Geng, S., Chen, M., Corke, H., \& Cai, Y.-Z. (2009). Effects of konjac glucomannan on physicochemical properties of myofibrillar protein and surimi gels from grass carp (Ctenopharyngodon idella). Food Chemistry, 116(2), 413-418. http://dx.doi.org/10.1016/j.foodchem.2009.02.056.

Yang, C. H., \& Lin, J. (2018). Effects of storage temperature and time on the glycemic response of white rice. Warasan Khana Witthayasat Maha Witthayalai Chiang Mai, 45(3), 1439-1448.

Yanuriati, A., Marseno, D. W., Rochmadi, \& Harmayani, E. (2017). Characteristics of glucomannan isolated from fresh tuber of Porang (Amorphophallus muelleri Blume). Carbohydrate Polymers, 156, 5663. http://dx.doi.org/10.1016/j.carbpol.2016.08.080. PMid:27842852.

Zazueta-Morales, J. J., Martínez-Bustos, F., Jacobo-Valenzuela, N., Ordorica-Falomir, C., \& Paredes-López, O. (2001). Effect of the addition of calcium hydroxide on some characteristics of extruded products from blue maize (Zea mays L) using response surface methodology. Journal of the Science of Food and Agriculture, 81(14), 1379-1386. http://dx.doi.org/10.1002/ jsfa.951.

Zhao, D., Zhou, Y., Liu, H., Liang, J., Cheng, Y., \& Nirasawa, S. (2017). Effects of dough mixing time before adding konjac glucomannan on the quality of noodles. Journal of Food Science and Technology, 54(12), 3837-3846. http://dx.doi.org/10.1007/s13197-017-2831-1. PMid:29085126.

Zhou, Y., Cao, H., Hou, M., Nirasawa, S., Tatsumi, E., Foster, T. J., \& Cheng, Y. (2013). Effect of konjac glucomannan on physical and sensory properties of noodles made from low-protein wheat flour. Food Research International, 51(2), 879-885. http://dx.doi. org/10.1016/j.foodres.2013.02.002. 